\title{
Small bowel enteroscopy
}

\author{
Christopher W Teshima MD¹, Gary May MD²
}

CW Teshima, G May. Small bowel enteroscopy. Can J Gastroenterol 2012;26(5):269-276.

Over the past decade, the advent of capsule endoscopy and balloonassisted enteroscopy has revolutionized the approach to small intestinal diseases. The small bowel is no longer out of reach, and has fallen within the diagnostic and therapeutic realm of the gastrointestinal endoscopist. Double-balloon enteroscopy was the first type of balloonassisted endoscopy and is the method for which there are the most data. Single-balloon enteroscopy has since been introduced as an alternative balloon-assisted method, followed more recently by the development of spiral overtube-assisted enteroscopy. The purpose of the present article is to review these methods of small bowel enteroscopy and to discuss the latest developments. While the investigation of small bowel diseases cannot be addressed without considering the central role of capsule endoscopy, a detailed assessment is beyond the scope of the present article, and capsule endoscopy will only be discussed as it pertains to enteroscopy.

Key Words: Capsule endoscopy; Double-balloon enteroscopy; Single balloon enteroscopy; Small bowel; Spiral enteroscopy

\section{TECHNIQUE AND EQUIPMENT}

By now, most readers have some familiarity with the basic concepts involved in double-balloon enteroscopy (DBE, Fujinon Inc, Japan). Briefly, DBE consists of a $200 \mathrm{~cm}$ endoscope and a $140 \mathrm{~cm}$ flexible, polyurethane overtube, both of which are fitted at the distal tip with an inflatable latex balloon (Figure 1A). The overtube balloon is inflated to grip the intestinal wall and hold it in place, preventing stretching of the intestine and enabling advancement of the endoscope without the formation of redundant loops of bowel. After advancement of the overtube to the distal tip of the endoscope, both balloons are simultaneously inflated while the endoscope and overtube are pulled back together in a shortening manoeuvre pleating the intestine back over the scope. This cycle is successively repeated as the endoscope is advanced through the small intestine. In contrast, singleballoon enteroscopy (SBE, Olympus Inc, Japan) (Figure 1B) is a latexfree system that has a balloon only on the overtube, meaning that endoscope tip deflection, usually together with suction, is required to 'hook' the bowel wall to enable shortening, whereas in DBE, this is accomplished directly by inflating the endoscope balloon. Both DBE and SBE may be performed via an anterograde approach through the mouth or via a retrograde approach through the anus. The techniques for performing DBE and SBE have been described in detail elsewhere $(1-4)$. Spiral enteroscopy is a new and entirely different overtubeassisted method for which the earliest outcomes are just beginning to be reported $(5,6)$. It uses a unique overtube called the Discovery SB (Spirus Medical Inc, USA), which has raised helices at its distal end,

\section{L'entéroscopie du grêle}

Depuis dix ans, l'avènement de l'endoscopie par capsule et de l'entéroscopie par ballonnet a révolutionné l'approche des maladies du grêle. Celui-ci n'est plus hors d'atteinte et fait désormais partie du domaine diagnostique et thérapeutique de l'endoscopiste gastrointestinal. L'entéroscopie à double ballonnet est le premier type d'endoscopie à ballonnet, est c'est la méthode pour laquelle on possède le plus de données. L'entéroscopie à simple ballonnet a ensuite été mise au point comme solution de rechange à la méthode assistée par ballonnet, suivie plus récemment par l'entéroscopie spiralée. Le présent article vise à analyser ces méthodes d'entéroscopie du grêle et à exposer les dernières découvertes. On ne peut aborder l'exploration des maladies du grêle sans envisager le rôle central de l'endoscopie par capsule, mais une évaluation détaillée dépasse la portée du présent article. Ainsi, l'endoscopie par capsule ne sera présentée qu'en ce qui a trait à l'entéroscopie.

\footnotetext{
${ }^{1}$ Division of Gastroenterology, University of Alberta, Edmonton, Alberta; ${ }^{2}$ Division of Gastroenterology, St Michael's Hospital, Toronto, Ontario
}

Correspondence: Dr Christopher W Teshima, 1-51 Zeidler Ledcor Centre, University of Alberta Hospital, Edmonton, Alberta T6G 2 X8.

Telephone 780-248-1673, fax 780-492-9416,e-mail teshima@ualberta.ca

Received for publication January 2, 2011. Accepted July 25, 2011 

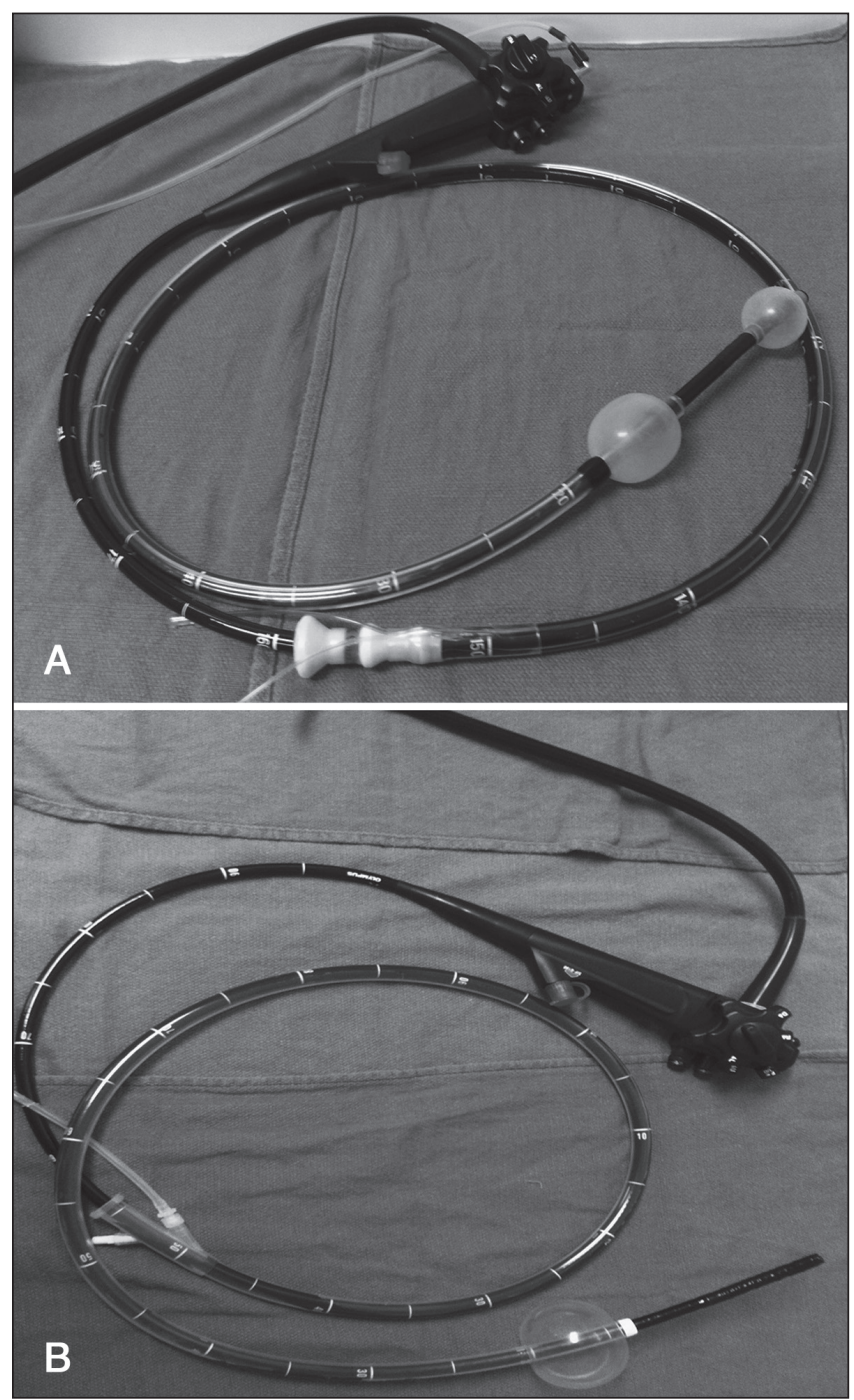

Figure 1) A Double-balloon endoscope. B Single-balloon endoscope

\section{COST}

Cost may be a significant factor when considering investment in a small bowel endoscopy system (Table 1), particularly for existing Olympus endoscopy users who would need to purchase a dedicated Fujinon platform if they decided to adopt DBE rather than SBE. Thus, for those already using Olympus endoscopes, there may be an economic argument for choosing SBE. For both systems, the overtube is a disposable, single-use device that must be used fresh for each case. Standard colonoscope accessories, including biopsy forceps, polypectomy snares, injector needles and 7 Fr argon plasma coagulation probes can be used with the SBE and therapeutic DBE (EN-450T5) endoscopes. Smaller, dedicated accessories are needed for the narrower channel in the pediatric DBE (EN-450P5) endoscope.

\section{TRAINING}

$\mathrm{BAE}$ is a challenging procedure associated with a significant learning curve and must be performed frequently and on a consistent basis to master. This was illustrated by the DBE experience of the Mayo Jacksonville group (9), for whom the rate of complete enteroscopy was $8 \%$ and DBE was deemed to have a "helpful clinical impact" for $58 \%$ of the first 50 cases, whereas for cases 150 to 200, the rates of complete enteroscopy and clinical impact rose to $63 \%$ and $86 \%$, respectively. Furthermore, in the first year of DBE performed at six tertiary referral centres in the United States (US) after experienced endoscopists had undergone a training course in Germany, stable insertion of the DBE
TABLE 1

Cost of small bowel endoscopy devices in Canada

\begin{tabular}{lr}
\hline Device & Price, \$CAD* \\
\hline Olympus single balloon system & \\
SIF-Q180 SBE endoscope & 49,500 \\
Balloon pump controller unit & 16,500 \\
Disposable overtube & 360 \\
Fujinon double balloon system & \\
EN-450T5 therapeutic DBE endoscope & 58,950 \\
EN-450P5 pediatric DBE endoscope & 55,750 \\
EC-450BI5 'short' DBE endoscope & 39,950 \\
Balloon pump controller unit & 27,750 \\
Endoscopy cart & 5,995 \\
Video processing unit & 42,250 \\
Disposable overtube & 345 \\
\hline
\end{tabular}

*Source: Olympus Canada Inc, Carsen Medical Inc. DBE Double-balloon enteroscopy; SBE Single-balloon enteroscopy

\section{TABLE 2}

Indications for small bowel endoscopy

\begin{tabular}{ll}
\hline Accepted indications & Indications under investigation \\
\hline Obscure gastrointestinal bleeding & Crohn's disease \\
Small bowel tumours & Refractory celiac disease \\
$\begin{array}{l}\text { Polyposis syndromes (eg, } \\
\text { Peutz-Jeghers, Familial }\end{array}$ & $\begin{array}{c}\text { Therapeutic colonoscopy (eg, } \\
\text { esophagastroduodenoscopy, }\end{array}$ \\
$\begin{array}{c}\text { adenomatous polyposis) } \\
\text { difficult polypectomy) } \\
\text { endoscopy or radiology }\end{array}$ & $\begin{array}{c}\text { Small bowel confocal } \\
\text { endomicroscopy or endoscopic } \\
\text { ultrasound with miniprobe }\end{array}$ \\
$\begin{array}{c}\text { Removal of foreign bodies from the } \\
\text { small intestine (eg, retained } \\
\text { capsule) }\end{array}$ & $\begin{array}{c}\text { Small bowel obstruction (diagnosis } \\
\text { and treatment) }\end{array}$ \\
$\begin{array}{l}\text { Dilation of small bowel stenoses } \\
\text { Access to pancreaticobiliary system } \\
\text { or excluded stomach in altered } \\
\text { postsurgical anatomy }\end{array}$ & $\begin{array}{l}\text { Percutaneous jejunostomy insertion } \\
\text { Incomplete or difficult colonoscopy pediatrics }\end{array}$ \\
\hline
\end{tabular}

endoscope through the ileocecal valve into the terminal ileum failed in $31 \%$ of cases (7). This steep learning curve has significant implications for training, meaning that BAE experience is likely best acquired during a dedicated endoscopy fellowship and not as part of a general gastroenterology residency. While there are no formal guidelines for the requisite training necessary to perform BAE, a recent American Society for Gastrointestinal Endoscopy (ASGE) technical review (10) suggests that advanced colonoscopy skill combined with dedicated and comprehensive training, preferably during a higher-tier advanced endoscopy fellowship, is necessary. The ASGE also contends that hands-on workshops alone cannot replace supervised training on human subjects. These recommendations have important implications for physicians in clinical practice interested in starting BAE because it implies the need to first devote time at another centre with a small bowel endoscopist already experienced with the technique.

\section{APPROACH TO GASTROINTESTINAL BLEEDING}

The indications for small bowel endoscopy are numerous and continue to expand (Table 2). However, the majority of patients are referred for the investigation of obscure gastrointestinal bleeding (OGIB) that remains unexplained after negative upper endoscopy and colonoscopy. In the past, such patients were evaluated with small bowel barium $\mathrm{x}$-ray and push enteroscopy, but the evidence now clearly demonstrates that these tests are grossly inferior to capsule endoscopy (CE) $(11,12)$ and to DBE $(13)$, and that proceeding immediately to DBE may be the most cost-effective strategy $(14,15)$. Nevertheless, the 
general consensus is that most patients with OGIB should be evaluated first by $\mathrm{CE}$, which can then select patients most likely to benefit from BAE or spiral enteroscopy. There are several reasons why the diagnostic strategy for OGIB in most cases should begin with CE:

- $\mathrm{CE}$ is relatively noninvasive and comfortable, whereas BAE procedures are very invasive and lengthy, typically lasting at least $100 \mathrm{~min}(7,9)$ and often associated with increased abdominal discomfort compared with conventional endoscopy (16).

- Patients may continue with their normal daily activities while undergoing $\mathrm{CE}$, whereas BAE requires deep sedation, usually with propofol, but in some Canadian centres with general anesthesia.

- Meta-analysis data demonstrate that CE and DBE have similar diagnostic yields for identifying the sources of small bowel bleeding (17-19).

- CE can accurately select the correct route of insertion for BAE (oral versus anal) based on the relative location of abnormal CE findings in terms of small bowel transit time, thus making subsequent BAE more efficient $(20,21)$.

- The diagnostic yield of DBE is significantly enhanced when performed after a previously positive CE (19).

- $\mathrm{CE}$ has a high negative predictive value, suggesting that most patients may be able to avoid undergoing BAE because the rebleeding rate after a negative $\mathrm{CE}$ study at 12 months follow-up is only $5 \%$ to $6 \%(22,23)$.

However, it must be remembered that $\mathrm{CE}$ can result in false-negative studies in which subsequent BAE may diagnose - and potentially treat the bleeding etiology. In particular, concerns have been raised about a possible tendency for CE to miss small bowel mass lesions such as tumours (24). This was illustrated by a retrospective study of small bowel mass lesions invovling 18 patients who were diagnosed using DBE (25). CE had been previously performed in 15 of these patients, but only detected the mass in five cases. Furthermore, CE visualizes the major papilla only $10 \%$ to $44 \%$ of the time, demonstrating how mass lesions have the potential to be missed $(26,27)$. Finally, a recent meta-analysis that examined comparative studies of DBE and CE in patients with OGIB (19) found that 29\% of patients with a negative CE had a bleeding source found with subsequent DBE. Therefore, when clinical suspicion is sufficiently high, or when patients have ongoing or recurrent evidence of bleeding after negative $\mathrm{CE}$, further investigation with small bowel enteroscopy is clearly warranted.

Another important consideration when referring patients for small bowel investigations for presumed OGIB is whether a second 're-look' gastroscopy and/or colonoscopy should be performed before CE or BAE. Studies involving both CE and DBE have demonstrated that as many as $25 \%$ of responsible bleeding sites are found within reach of a conventional gastroscope or colonoscope, with the most commonly identified lesions being gastric and duodenal ulcers, gastric antral vascular ectasia and colonic angiodysplasias (28-30). With this is mind, 're-look' endoscopy should be strongly considered before referral for CE or BAE.

\section{ENDOSCOPIC OUTCOMES}

Nearly all of the data that exist for small bowel enteroscopy come from DBE studies, with only early outcomes reported for SBE and spiral enteroscopy. DBE yields a positive diagnosis when investigating small bowel diseases approximately $70 \%$ of the time, resulting in immediate endoscopic therapy or a subsequent change in management in twothirds of positive cases $(2,7,9,31-37)$. The most commonly identified pathology among patients investigated for bleeding indications are vascular lesions such as angiodysplasia, inflammatory lesions such as ulcers, and tumours or polyps. Much less data exist for SBE, but early studies suggest a diagnostic yield of $41 \%$ to $65 \%$, with $50 \%$ to $60 \%$ of cases being able to provide therapeutic interventions, rates comparable with what has been achieved using DBE $(3,38-40)$. Much is often made about depths of insertion when comparing methods of small bowel endoscopy, yet despite a standardized method for estimating the extent of insertion (41), this remains a highly subjective measure. A more objective metric is the rate of complete enteroscopy when the entire small intestine is visualized by combining oral and anal approaches. This itself is highly variable for DBE, ranging from as low as $5 \%$ in the early US experience (7), to $23 \%$ in Germany (42) and to as high as $86 \%$ in the study by Yamamoto et al (2), the first pioneer of DBE, in Japan. In contrast, rates of complete enteroscopy using SBE have, to date, been limited to $0 \%$ to $25 \%(3,38-40)$. A recent study sought to compare the single- and double-balloon techniques by randomly assigning patients to undergo DBE or a 'single-balloon' method using the Fujinon DBE and overtube but without a balloon attached to the endoscope to simulate SBE (43). The rate of complete enteroscopy in the DBE group was $66 \%$ compared with $22 \%$ in the 'single balloon' group $(\mathrm{P}<0.0001)$. However, this study has been criticized for using endoscopists with extensive experience in DBE but much less with SBE and for simulating the single-balloon technique instead of actually using the Olympus SBE system, and likely does not represent a true comparison of these competing technologies. These limitations were overcome by a clinical trial from Japan that randomly assigned 38 patients to SBE or DBE, and found a complete enteroscopy rate of $0 \%$ and $57 \%$, respectively $(\mathrm{P}=0.002)(8)$. In fact, this trial was stopped early due to the obvious advantage for the DBE group. Conversely, a multicentre European noninferiority trial that randomly assigned patients to SBE versus DBE found no difference in proximal or distal insertion depths with either method, with rates of complete enteroscopy of $11 \%$ for SBE and $18 \%$ for DBE (44). Nevertheless, based on our own experience, it is not surprising to observe that SBE seems to have inferior insertion depths when compared with DBE, likely because the SBE hooking manoeuvre with the endoscope tip is less effective at grasping the bowel wall than inflation of the balloon at the tip of the endoscope in DBE, causing the SBE to slip during reduction cycles. However, achieving complete enteroscopy is often not clinically important or necessary, particularly when the majority of lesions, at least in patients in the western world, seem to be found in the proximal small intestine (37). Indeed, the rates of positive diagnoses between the DBE and the SBE groups in the previously mentioned studies were not significantly different despite the impressive difference in rates of complete enteroscopy in the first two of these trials (diagnostic yields of $52 \%$ for $\mathrm{DBE}$ and $42 \%$ for SBE [P=0.42] in the Wiesbaden study [43]; $50 \%$ for DBE and $61 \%$ for SBE [P=0.49] in the Japanese study [8]). However, achieving complete enteroscopy may provide greater reassurance against the possibility of rebleeding in subsequent follow-up compared with when parts of the small bowel remain unexamined (45).

Endoscopic outcomes are only beginning to be defined for spiral enteroscopy, the latest method of small bowel endoscopy. Preliminary reports described low diagnostic yields despite significant small bowel insertion depths and rapid average procedural times (5). However, recent studies have demonstrated improved outcomes similar to those obtained with DBE and SBE (46). Furthermore, studies directly comparing spiral enteroscopy via the oral route with SBE (47) and with DBE $(48,49)$ have now been published with somewhat conflicting results, although diagnostic yields did not significantly differ among methods. The only prospective randomized study found significantly shorter procedure times with spiral enteroscopy, but significantly greater insertion depths with DBE (49). Even less is known about the efficacy of spiral enteroscopy performed via the anal route. Although this has been shown to be a feasible technique (50), we expect deep insertion using this method to be limited because the spiral overtube itself is unable to pass through the ileocecal valve in a retrograde fashion. Thus, while spiral enteroscopy has potentially great appeal due to its shorter insertion times, its comparative efficacy still needs to be clarified before adoption in clinical settings.

\section{CLINICAL OUTCOMES}

A more important consideration regarding small bowel enteroscopy is the question of how clinically useful these investigations are to 
patients in the long term. In fact, very little data regarding long-term follow-up of patients after DBE exist, with most studies having focused on immediate endoscopic results. In a telephone survey of 274 patients who had undergone DBE for OGIB in which $31 \%$ agreed to participate in an interview at 30 months' follow-up, 59\% experienced no further bleeding or anemia, $28 \%$ had an ongoing need for blood transfusions or iron therapy, and $24 \%$ experienced new or recurrent overt bleeding (51). Among patients found to have arteriovenous malformations, $57 \%$ experienced rebleeding, or required transfusions and/or iron therapy at 12 months' follow-up. More rigorous data come from a recent retrospective analysis of 151 patients who underwent DBE for OGIB in Japan. At a mean long-term follow-up of 29.7 months, 63\% of patients with a negative DBE had 'control' of bleeding, defined as the absence of overt bleeding, a drop in hemoglobin $>10 \mathrm{~g} / \mathrm{L}$, and blood transfusions or iron therapy (52). In contrast, patients found to have vascular lesions on DBE were most likely to experience rebleeding and had significantly shorter rebleeding-free intervals, with $40 \%$ experiencing a recurrent overt bleed within one year of their DBE and only $40 \%$ with 'control' of OGIB at long-term follow-up. The significant predictors of rebleeding among these patients with vascular lesions were a large transfusion requirement before the initial DBE (mean of 9.7 units in patients with overt rebleeding versus 3.3 units in patients without overt rebleeding $[\mathrm{P}=0.012]$ ), the finding of multiple vascular lesions compared with a solitary vascular lesion $(\mathrm{P}=0.01)$ and the identification of 'suspicious' as opposed to 'definite' causative lesions $(\mathrm{P}=0.038)$, perhaps because these inconclusive lesions were not endoscopically treated. Meanwhile, patients with other findings on DBE seem to experience better long-term outcomes, with $65 \%$ control in those with ulcers/erosions and $84 \%$ control in those with tumours or polyps (52). It appears that patients with OGIB due to vascular lesions are the most difficult to treat, and the most likely to experience recurrent or ongoing bleeding, suggesting that ongoing clinical follow-up is likely required for this group. Nevertheless, the superior outcomes in patients with other diagnoses and the need to exclude more sinister causes of bleeding such as small bowel tumours, which may be present in as many as $5 \%$ to $10 \%$ of OGIB patients $(53,54)$, illustrates the importance of performing some form of small bowel endoscopy, be it DBE, SBE or CE.

\section{SAFETY AND COMPLICATIONS}

Given the deeply invasive nature of BAE, it is perhaps not surprising to observe complication rates that exceed those encountered with colonoscopy. A large, multicentre survey of 10 institutions in Europe and Asia involving 2362 DBE procedures (55) identified bleeding $(0.8 \%)$, perforation $(0.3 \%)$ and pancreatitis $(0.3 \%)$ as the most common and significant adverse events associated with DBE. Overall, complications were more frequently encountered with therapeutic $(4.3 \%)$ rather than diagnostic $(0.8 \%)$ procedures, with 12 of 19 bleeding episodes occurring after polypectomy and five of six perforations occurring after an intervention (two postdilation, three post-argon plasma coagulation). Rates of pancreatitis did not differ between diagnostic and therapeutic procedures but were confined to patients who had undergone anterograde DBE. A similar pattern was observed in $2478 \mathrm{DBE}$ procedures performed at nine centres in the US, where the most notable adverse events remained: perforation $(0.4 \%)$, bleeding $(0.2 \%)$ and pancreatitis $(0.2 \%)(56)$. However, a striking finding of this study was the preponderance of perforations occurring in retrograde DBE procedures performed in patients with surgically altered anatomies, most in purely diagnostic examinations. The perforation rate was much higher in retrograde $(1.1 \%)$ compared with antegrade $(0.2 \%)$ cases, with one-half of such perforations in the retrograde procedure occurring in patients with previous ileoanal or ileocolonic anastomoses. In fact, among this subgroup with a surgically altered anatomy, perforations occurred in six of $60(10 \%)$ retrograde but only one of $159(0.6 \%)$ anterograde DBE cases. This finding should raise alarm and signal endoscopists to heed caution when performing retrograde DBE in this patient population. In the early years of BAE, much of the attention regarding complications focused on the occurrence of post-DBE pancreatitis. In response to these concerns, the DBE insertion technique was modified to delay balloon inflation until the tips of both the endoscope and overtube are beyond the ligament of Treitz, which appears to have decreased the incidence of pancreatitis, but asymptomatic hyperamylasemia remains common (57). Indeed, in the first studies of adverse events with SBE and spiral enteroscopy, no episodes of pancreatitis were encountered $(58,59)$. Thus, while pancreatitis continues to be a present, yet possibly diminishing, concern, bleeding and, in particular, perforation, remain major adverse events that must be considered before performing BAE and spiral enteroscopy.

\section{EMERGING APPLICATIONS}

\section{Biliary and pancreatic access in surgically altered anatomy}

Endoscopic retrograde cholangiopancreatography (ERCP) in patients after partial gastrectomy with Billroth II gastrojejunostomy or after Roux-en-Y anastomosis (for a variety of surgical indications including Whipple resection, liver transplant and gastric bypass) has long been challenging, particularly in achieving access to the native papilla or pancreatic and/or biliary surgical anastomosis. Over the past few years, the feasibility, safety and efficacy of the new BAE methods to facilitate ERCP have been demonstrated, predominantly in the form of small case series with DBE. Several studies have reported success rates of $80 \%$ to $90 \%$ (60-63), whereas other series have had much lower success rates in the range of $60 \%$ to $63 \%$ (64-66). Similar cannulation success rates of between $62 \%$ and $75 \%$ have also been reported from early case series of SBE-assisted ERCP (67-71). A multicentre, retrospective study compared the use of DBE, SBE and spiral enteroscopy to facilitate $156 \mathrm{ERCP}$ procedures conducted in 129 long-limb surgical bypass patients (72), and no difference was observed among the methods, with overall success rates of $71 \%$ for enteroscopy (in terms of reaching the native papilla or pancreatic and/or biliary anastomosis) and 63\% for ERCP cannulation. Indeed, achieving successful cannulation is one of the unique challenges posed by BAE-assisted ERCP, particularly because of the use of a forward-viewing rather than a side-viewing endoscope and because of the lack of an elevator (73). An additional challenge has been the need for dedicated ERCP accessories long enough to be used with the $200 \mathrm{~cm}$ DBE or SBE endoscopes. To overcome this limitation, a 'short' $152 \mathrm{~cm}$ DBE endoscope with a $2.8 \mathrm{~mm}$ working channel (EC-450BI5 [Fujinon Inc, Japan]) that is compatible with conventional ERCP accessories has been developed. Early data from one expert Japanese centre demonstrated exceptional outcomes, with ERCP access achieved in $97 \%$ and successful cannulation in $95 \%$ of 103 short-DBE ERCP cases (74). In summary, while the new methods of BAE and spiral enteroscopy can be effectively used to facilitate ERCP in patients with surgically altered anatomy, the procedure remains challenging.

\section{Incomplete colonoscopy}

Another useful, emerging application of BAE is the completion of colonoscopy in patients with previously failed or difficult colonoscopy. Several case series have demonstrated the efficacy and safety of using $\mathrm{DBE}$ or SBE endoscopes to perform colonoscopy in patients in whom often multiple previous attempts with conventional colonoscopy failed to reach the cecum (75-79). Among these cohorts, successful cecal intubation was achieved in more than $95 \%$ of cases, with no reported complications. While there has not yet been a head-to-head comparison of DBE- and SBE-assisted colonoscopy, a small, single-centre, randomized controlled trial comparing SBE with repeat standard colonoscopy (SC) in 30 patients with previously failed colonoscopy was recently published (80). The cecal intubation rate was $93 \%$ and $50 \%$ for SBE and SC, respectively, with success rates for reaching the cecum by crossing over to the alternative technique of $100 \%$ for SBE and 0\% for SC. However, a retrospective review of 90 patients with previously incomplete colonoscopy referred to St Paul's Hospital (Vancouver, British Columbia) between 2005 and 2010, showed that repeat attempts at colonoscopy were successful in $97 \%$ of cases (81). Thus, it 
is important to emphasize that while balloon-assisted methods are useful options when complete colon examination cannot be achieved, the vast majority of incomplete colonoscopies can be overcome with the use of increased sedation, more time and patience, variable-stiffness or pediatric colonoscopes, or referral to a more experienced endoscopist.

\section{SUMMARY}

Over the past decade, the advent of DBE, SBE and spiral enteroscopy has revolutionized the accessibility and approach to small bowel diseases, extending beyond the diagnostic capabilities of radiology or CE to enable real-time access, tissue sampling and therapeutic interventions deep within the small intestine. While small bowel enteroscopy was an experimental field only a few years ago, it has now become firmly established as a key component in the evaluation of the gastrointestinal tract (Table 3). What remains unclear is how the various methods truly compare, and the clinical - not just endoscopic - outcomes that are achieved by performing these invasive and time-consuming procedures. Well-designed, prospective, randomized controlled trials with long-term follow-up are needed to provide this clarity. In the meantime, DBE remains the standard for which most data exist, and SBE and spiral enteroscopy will likely continue to be regarded as experimental methods that still need to be shown to be as good as DBE before being adopted outside of a research setting.

\section{REFERENCES}

1. Yamamoto H, Sekine Y, Sato Y, et al. Total enteroscopy with a nonsurgical steerable double-balloon method. Gastrointest Endosc 2001;53:216-20.

2. Yamamoto H, Kita H, Sunada K, et al. Clinical outcomes of double-balloon endoscopy for the diagnosis and treatment of small-intestinal diseases. Clin Gastroenterol Hepatol 2004;2:1010-6.

3. Tsujikawa T, Saitoh Y, Andoh A, et al. Novel single-balloon enteroscopy for diagnosis and treatment of the small intestine: Preliminary experiences. Endoscopy 2008;40:11-5.

4. Lo SK. Techniques, tricks, and complications of enteroscopy. Gastrointest Endosc Clin N Am 2009;19:381-8.

5. Akerman PA, Agrawal D, Cantero D, Pangtay J. Spiral enteroscopy with the new DSB overtube: A novel technique for deep peroral small-bowel intubation. Endoscopy 2008;40:974-8.

6. Akerman PA, Agrawal D, Chen W, Cantero D, Avila J, Pangtay J. Spiral enteroscopy: A novel method of enteroscopy by using the Endo-Ease Discovery SB overtube and a pediatric colonoscope. Gastrointest Endosc 2009;69:327-32.

7. Mehdizadeh S, Ross A, Gerson L, et al. What is the learning curve associated with double-balloon enteroscopy? Technical details and early experience in 6 U.S. tertiary care centers. Gastrointest Endosc 2006;64:740-50.

8. Takano N, Yamada A, Watabe H, et al. Single-balloon versus double-balloon endoscopy for achieving total enteroscopy: A randomized, controlled trial. Gastrointest Endosc 2011;73:734-9.

9. Gross SA, Stark ME. Initial experience with double-balloon enteroscopy at a U.S. center. Gastrointest Endosc 2008;67:890-7.

10. Buscaglia JM, Okolo PI. Deep enteroscopy: Training, indications, and the endoscopic technique. Gastrointest Endosc 2011;73:1023-8.

11. Triester SL, Leighton JA, Leontiadis GI, et al. A meta-analysis of the yield of capsule endoscopy compared to other diagnostic modalities in patients with obscure gastrointestinal bleeding. Am J Gastroenterol 2005;100:2407-18.

12. de Leusse A, Vahedi K, Edery J, et al. Capsule endoscopy or push enteroscopy for first-line exploration of obscure gastrointestinal bleeding? Gastroenterology 2007;132:855-62.

13. May A, Nachbar L, Schneider M, Ell C. Prospective comparison of push enteroscopy and push-and-pull enteroscopy in patients with suspected small-bowel bleeding. Am J Gastroenterol 2006;101:2016-24.

14. Gerson L, Kamal A. Cost-effectiveness analysis of management strategies for obscure GI bleeding. Gastrointest Endosc 2008;68:920-36.

15. Somsouk M, Gralnek IM, Inadomi JM. Management of obscure occult gastrointestinal bleeding: A cost-minimization analysis. Clin Gastroenterol Hepatol 2008;6:661-70.

\section{TABLE 3}

\section{Summary of key messages}

BAE is safe and effective, enabling real-time diagnosis, tissue sampling and therapeutics throughout the small bowel

Assessment for small bowel sources of bleeding should begin with $\mathrm{CE}$, followed by BAE when CE yields positive findings or when clinical suspicion remains high

Most data exist for DBE, but evidence continues to emerge for SBE and spiral enteroscopy

Randomized controlled trials comparing DBE and SBE show superior rates of 'complete enteroscopy' for DBE but equivalent diagnostic yields

There is a paucity of data regarding long-term clinical outcomes and benefit from BAE for small bowel bleeding

The major complications from BAE are perforation $(0.3 \%-0.4 \%)$, pancreatitis $(0.2 \%-0.3 \%)$ and bleeding $(0.2 \%-0.8 \%)$

BAE Balloon-assisted enteroscopy; CE Capsule endoscopy; DBE Doubleballoon enteroscopy; SBE Single-balloon enteroscopy

DISCLOSURES: The authors have no financial disclosures or conflicts of interest to declare.

16. Byeon J, Jung $\mathrm{K}$, Song $\mathrm{H}$, et al. A pilot study about tolerability to double balloon endoscopy: Comparison to esophagogastroduodenoscopy and colonoscopy. Dig Dis Sci 2009;54:2434-40.

17. Pasha SF, Leighton JA, Das A, et al. Double-balloon enteroscopy and capsule endoscopy have comparable diagnostic yield in smallbowel disease: A meta-analysis. Clin Gastroenterol Hepatol 2008;6:671-6.

18. Chen X, Ran Z-H, Tong J-L. A meta-analysis of the yield of capsule endoscopy compared to double-balloon enteroscopy in patients with small bowel diseases. World J Gastroenterol 2007;13:4372-8.

19. Teshima CW, Kuipers EJ, van Zanten SV, Mensink PBF. Double balloon enteroscopy and capsule endoscopy for obscure gastrointestinal bleeding: An updated meta-analysis. J Gastroenterol Hepatol 2011;26:796-801.

20. Gay G, Delvaux M, Fassler I. Outcome of capsule endoscopy in determining indication and route for push-and-pull enteroscopy. Endoscopy 2006;38:49-58.

21. Li X, Chen H, Dai J, Gao Y, Ge Z. Predictive role of capsule endoscopy on the insertion route of double-balloon enteroscopy. Endoscopy 2009;41:762-6.

22. Lewis BS, Eisen GM, Friedman S. A pooled analysis to evaluate results of capsule endoscopy trials. Endoscopy 2005;37:960-5.

23. Lai LH, Wong GLH, Chow DKL, Lau JYW, Sung JJY, Leung WK. Long-term follow-up of patients with obscure gastrointestinal bleeding after negative capsule endoscopy. Am J Gastroenterol 2006;101:1224-8.

24. Postgate A, Despott E, Burling D, et al. Significant small-bowel lesions detected by alternative diagnostic modalities after negative capsule endoscopy. Gastrointest Endosc 2008;68:1209-14.

25. Ross A, Mehdizadeh S, Tokar J, et al. Double balloon enteroscopy detects small bowel mass lesions missed by capsule endoscopy. Dig Dis Sci 2008;53:2140-3.

26. Kong H, Kim YS, Hyun JJ, et al. Limited ability of capsule endoscopy to detect normally positioned duodenal papilla. Gastrointest Endosc 2006;64:538-41.

27. Clarke JO, Giday SA, Magno P, et al. How good is capsule endoscopy for detection of periampullary lesions? Results of a tertiary-referral center. Gastrointest Endosc 2008;68:267-72.

28. Fry LC, Bellutti M, Neumann H, Malfertheiner P, Mönkemüller K. Incidence of bleeding lesions within reach of conventional upper and lower endoscopes in patients undergoing double-balloon enteroscopy for obscure gastrointestinal bleeding. Aliment Pharmacol Ther 2009;29:342-9.

29. Elijah D, Daas A, Brady P. Capsule endoscopy for obscure GI bleeding yields a high incidence of significant treatable lesions within reach of standard upper endoscopy. J Clin Gastroenterol 2008;42:962-3. 
30. Tee H-P, Kaffes AJ. Non-small-bowel lesions encountered during double-balloon enteroscopy performed for obscure gastrointestinal bleeding. World J Gastroenterol 2010;16:1885-9.

31. Ell C, May A, Nachbar L, et al. Push-and-pull enteroscopy in the small bowel using the double-balloon technique: Results of a prospective European multicenter study. Endoscopy 2005;37:613-6.

32. May A, Nachbar L, Ell C. Double-balloon enteroscopy (push-andpull enteroscopy) of the small bowel: Feasibility and diagnostic and therapeutic yield in patients with suspected small bowel disease. Gastrointest Endosc 2005;62:62-70.

33. Hadithi M, Heine GDN, Jacobs MAJM, van Bodegraven AA, V Bodegraven AA, Mulder CJJ. A prospective study comparing video capsule endoscopy with double-balloon enteroscopy in patients with obscure gastrointestinal bleeding. Am J Gastroenterol 2006;101:52-7.

34. Monkemuller K, Weigt J, Treiber G, et al. Diagnostic and therapeutic impact of double-balloon enteroscopy. Endoscopy 2006;38:67-72.

35. Sun B, Rajan E, Cheng S, et al. Diagnostic yield and therapeutic impact of double-balloon enteroscopy in a large cohort of patients with obscure gastrointestinal bleeding. Am J Gastroenterol 2006;101:2011-5.

36. Ohmiya N, Yano T, Yamamoto $\mathrm{H}$, et al. Diagnosis and treatment of obscure GI bleeding at double balloon endoscopy. Gastrointest Endosc 2007;66:S72-7.

37. Heine GD, Hadithi M, Groenen MJ, Kuipers EJ, Jacobs MA, Mulder CJ. Double-balloon enteroscopy: Indications, diagnostic yield, and complications in a series of 275 patients with suspected small-bowel disease. Endoscopy 2006;38:42-8.

38. Kawamura T, Yasuda K, Tanaka K, et al. Clinical evaluation of a newly developed single-balloon enteroscope. Gastrointest Endosc 2008;68:1112-6.

39. Ramchandani M, Reddy D, Gupta R, et al. Diagnostic yield and therapeutic impact of single-balloon enteroscopy: Series of 106 cases. J Gastroenterol Hepatol 2009;24:1631-8.

40. Upchurch BR, Sanaka MR, Lopez AR, Vargo JJ. The clinical utility of single-balloon enteroscopy: A single-center experience of 172 procedures. Gastrointest Endosc 2010;71:1218-23.

41. May A, Nachbar L, Schneider M, Neumann M, Ell C. Push-and-pull enteroscopy using the double-balloon technique: Method of assessing depth of insertion and training of the enteroscopy technique using the Erlangen Endo-Trainer. Endoscopy 2005;37:66-70.

42. Möschler O, May A, Müller MK, Ell C, Group ftGDS. Complications in and performance of double-balloon enteroscopy (DBE): Results from a large prospective DBE database in Germany. Endoscopy 2011;43:484-9.

43. May A, Färber M, Aschmoneit I, et al. Prospective multicenter trial comparing push-and-pull enteroscopy with the single- and doubleballoon techniques in patients with small-bowel disorders. Am J Gastroenterol 2010;105:575-81.

44. Domagk D, Mensink P, Aktas H, et al. Single- vs. double-balloon enteroscopy in small-bowel diagnostics: A randomized multicenter trial. Endoscopy 2011;43:472-6.

45. Takayoshi S, Shiro O, Shinji T, et al. Clinical outcome of patients who have undergone total enteroscopy for obscure gastrointestinal bleeding. Gastrointest Endosc 2010;71:AB366 (Abst).

46. Morgan D, Upchurch B, Draganov P, et al. Spiral enteroscopy: Prospective U.S. multicenter study in patients with small-bowel disorders. Gastrointest Endosc 2010;72:992-8.

47. Khashab MA, Lennon AM, Dunbar KB, et al. A comparative evaluation of single-balloon enteroscopy and spiral enteroscopy for patients with mid-gut disorders. Gastrointest Endosc 2010;72:766-72.

48. Frieling T, Heise J, Sassenrath W, Hülsdonk A, Kreysel C. Prospective comparison between double-balloon enteroscopy and spiral enteroscopy. Endoscopy 2010;42:885-8.

49. May A, Manner H, Aschmoneit I, Ell C. Prospective, cross-over, single-center trial comparing oral double-balloon enteroscopy and oral spiral enteroscopy in patients with suspected small-bowel vascular malformations. Endoscopy 2011;43:477-83.

50. Akerman PA, Cantero D, Pangtay J, et al. Retrograde small bowel enteroscopy using the Olympus SIF-140 $260 \mathrm{~cm}$ enteroscope and the Vista-SB spiral overtube. Gastrointest Endosc 2009;69:AB201 (Abst).
51. Gerson L, Batenic M, Ross A, Semrad C. Long-term outcomes after double balloon enteroscopy for obscure gastrointestinal bleeding. Clin Gastroenterol Hepatol 2009; 7:664-9.

52. Shinozaki S, Yamamoto H, Yano T, et al. Long-term outcome of patients with obscure gastrointestinal bleeding investigated by double balloon endoscopy. Clin Gastroenterol Hepatol 2010;8:151-8.

53. Fry L, Neumann H, Kuester D, et al. Small bowel polyps and tumours: Endoscopic detection and treatment by double-balloon enteroscopy. Aliment Pharmacol Ther 2008;29:135-42.

54. Mitsui K, Tanaka S, Yamamoto H, et al. Role of double-balloon endoscopy in the diagnosis of small-bowel tumors: The first Japanese multicenter study. Gastrointest Endosc 2009;70:498-504.

55. Mensink PBF, Haringsma J, Kucharzik T, et al. Complications of double balloon enteroscopy: A multicenter survey. Endoscopy 2007;39:613-5.

56. Gerson LB, Tokar J, Chiorean M, et al. Complications associated with double balloon enteroscopy at nine US centers. Clin Gastroenterol Hepatol 2009;7:1177-82, 1182.e1-3.

57. Aktas H, Mensink PBF, Haringsma J, Kuipers EJ. Low incidence of hyperamylasemia after proximal double-balloon enteroscopy: Has the insertion technique improved? Endoscopy 2009;41:670-3.

58. Aktas H, de Ridder L, Haringsma J, Kuipers EJ, Mensink PB. Complications of single-balloon enteroscopy: A prospective evaluation of 166 procedures. Endoscopy 2010;42:365-8.

59. Akerman PA, Cantero D. Severe complications of spiral enteroscopy in the first 1750 patients. Gastrointest Endosc 2009;69:AB127 (Abst).

60. Emmett D, Mallat D. Double-balloon ERCP in patients who have undergone Roux-en-Y surgery: A case series. Gastrointest Endosc 2007;66:1038-41.

61. Aabakken L, Bretthauer M, Line P. Double-balloon enteroscopy for endoscopic retrograde cholangiography in patients with a Rouxen-Y anastomosis. Endoscopy 2007;39:1068-1071.

62. Mönkemüller K, Fry L, Bellutti M, Neumann H, Malfertheiner P. ERCP with the double balloon enteroscope in patients with Rouxen-Y anastomosis. Surg Endosc 2009;23:1961-7.

63. Pohl J, May A, Aschmoneit I, Ell C. Double-balloon endoscopy for retrograde cholangiography in patients with choledochojejunostomy and Roux-en-Y reconstruction. Zeitschrift fur Gastroenterologie 2009;47:215-9.

64. Maaser C, Lenze F, Bokemeyer M, et al. Double balloon enteroscopy: A useful tool for diagnostic and therapeutic procedures in the pancreaticobiliary system. Am J Gastroenterol 2008;103:894-900.

65. Chu Y-C, Yang C-C, Yeh Y-H, Chen C-H, Yueh S-K. Double-balloon enteroscopy application in biliary tract disease its therapeutic and diagnostic functions. Gastrointest Endosc 2008;68:585-91.

66. Moreels TG, Hubens GJ, Ysebaert DK, Op de Beeck B, Pelckmans PA. Diagnostic and therapeutic double-balloon enteroscopy after small bowel Roux-en-Y reconstructive surgery. Digestion 2009;80:141-7.

67. Neumann H, Fry LC, Meyer F, Malfertheiner P, Monkemuller K. Endoscopic retrograde cholangiopancreatography using the single balloon enteroscope technique in patients with Roux-en-Y anastomosis. Digestion 2009;80:52-7.

68. Dellon ES, Kohn GP, Morgan DR, Grimm IS. Endoscopic retrograde cholangiopancreatography with single-balloon enteroscopy is feasible in patients with a prior Roux-en-Y anastomosis. Dig Dis Sci 2009;54:1798-803.

69. Itoi T, Ishii K, Sofuni A, et al. Single-balloon enteroscopy-assisted ERCP in patients with Billroth II gastrectomy or Roux-en-Y anastomosis (with video). Am J Gastroenterol 2010;105:93-9.

70. Wang AY, Sauer BG, Behm BW, et al. Single-balloon enteroscopy effectively enables diagnostic and therapeutic retrograde cholangiography in patients with surgically altered anatomy. Gastrointest Endosc 2010;71:641-9.

71. Saleem A, Baron TH, Gostout CJ, et al. Endoscopic retrograde cholangiopancreatography using a single-balloon enteroscope in patients with altered Roux-en-Y anatomy. Endoscopy 2010;42:656-60.

72. Shah RJ, Smolkin M, Ross AS, et al. A multi-center, United States experience of single balloon, double balloon, and rotational overtube enteroscopy-assisted ERCP in long limb surgical bypass patients. Gastrointest Endosc 2010;71:AB134-5 (Abst).

73. Haber GB. Double balloon endoscopy for pancreatic and biliary access in altered anatomy (with videos). Gastrointest Endosc 2007;66:S47-50. 
74. Shimatani M, Matsushita M, Takaoka M, et al. Effective "short" double-balloon enteroscope for diagnostic and therapeutic ERCP in patients with altered gastrointestinal anatomy: A large case series. Endoscopy 2009;41:849-54.

75. Kaltenbach T, Soetikno R, Friedland S. Use of a double balloon enteroscope facilitates caecal intubation after incomplete colonoscopy with a standard colonoscope. Dig Liver Dis 2006;38:921-5.

76. Gay G, Delvaux M. Double-balloon colonoscopy after failed conventional colonoscopy: A pilot series with a new instrument. Endoscopy 2007;39:788-792.

77. Pasha SF, Harrison ME, Das A, Corrado CM, Arnell KN, Leighton JA. Utility of double-balloon colonoscopy for completion of colon examination after incomplete colonoscopy with conventional colonoscope. Gastrointest Endosc 2007;65:848-53.
78. Moreels T, Macken E, Roth B, Van Outryve M, Pelckmans P. Cecal intubation rate with the double-balloon endoscope after incomplete conventional colonoscopy: A study in 45 patients. J Gastroenterol Hepatol 2010;25:80-3.

79. Teshima CW, Aktas H, Haringsma J, Kuipers EJ, Mensink PBF. Single-balloon-assisted colonoscopy in patients with previously failed colonoscopy. Gastrointest Endosc 2010;71:1319-23.

80. Keswani RN. Single-balloon colonoscopy versus repeat standard colonoscopy for previous incomplete colonoscopy: A randomized, controlled trial. Gastrointest Endosc 2011;73:507-12.

81. Brahmania M, Park J, Svarta S, Tong J, Kwok R, Enns R. Incomplete colonoscopy: Past, present, and beyond. Can J Gastroenterol 2011;25(SupplA):A146 (Abst). 


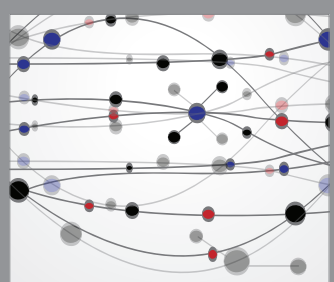

The Scientific World Journal
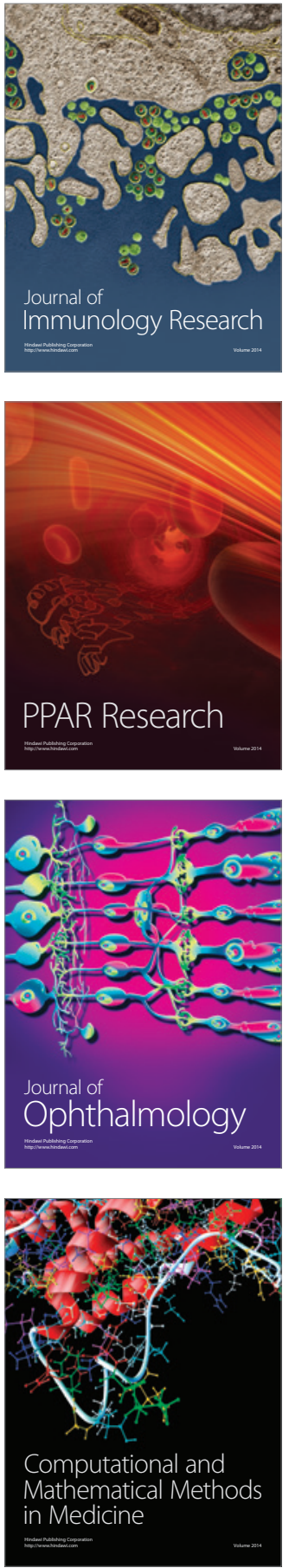

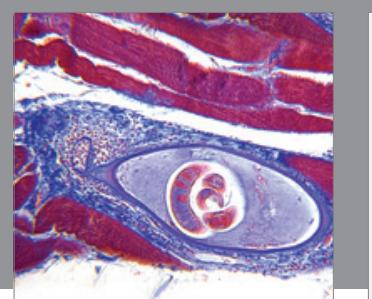

Gastroenterology Research and Practice

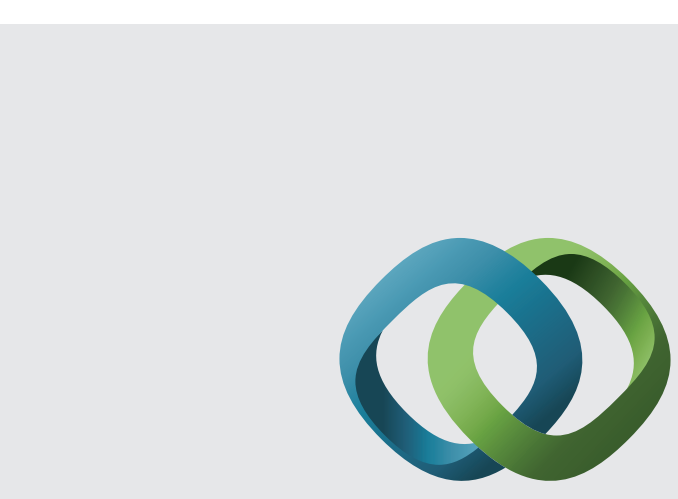

\section{Hindawi}

Submit your manuscripts at

http://www.hindawi.com
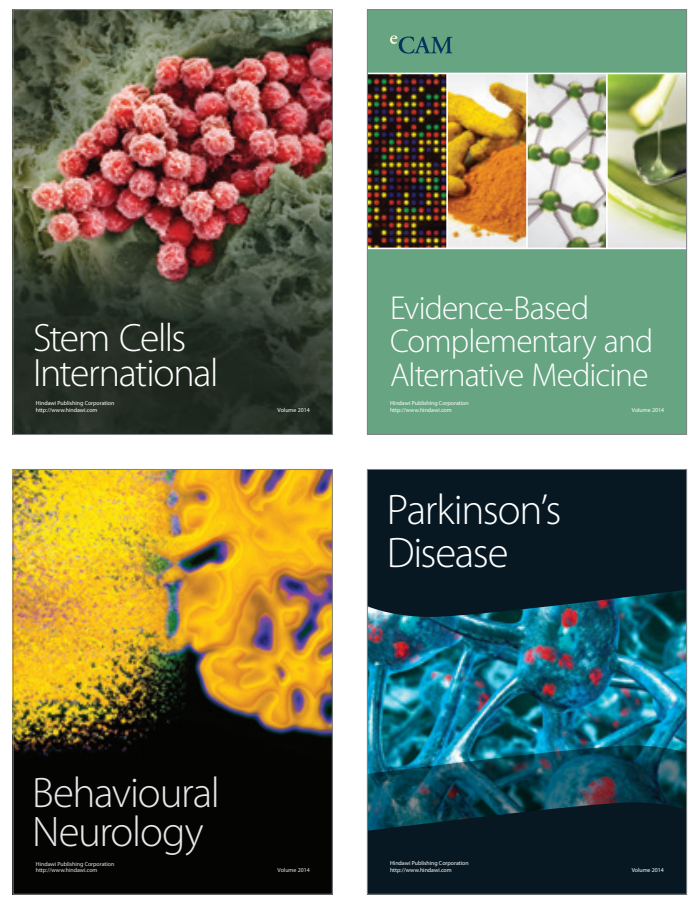
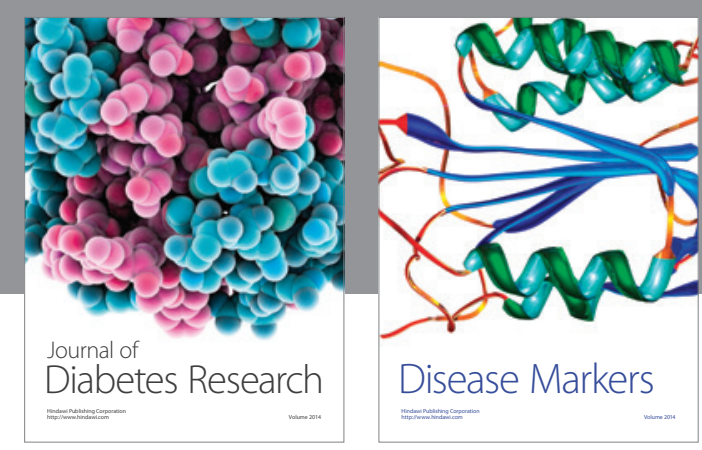

Disease Markers
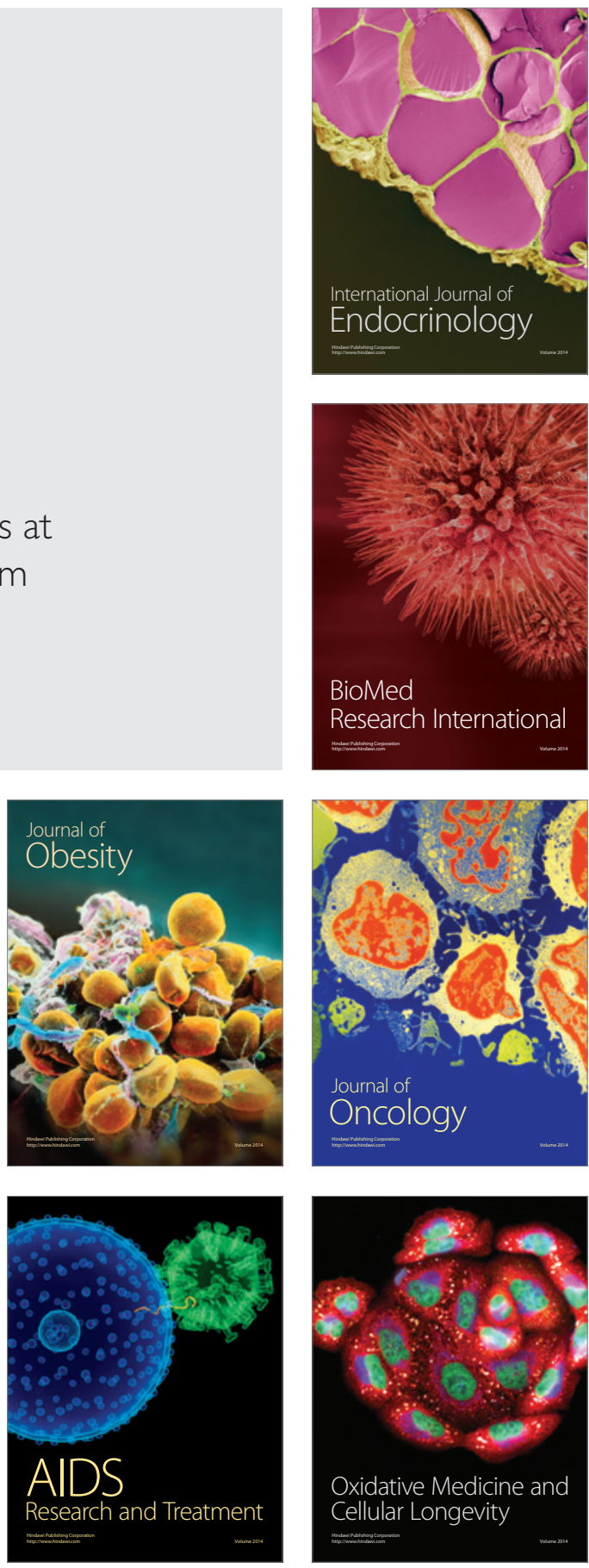